\title{
4
}

\section{Onstage and Off: The Shifting Relevance of Gender in Women's Prisons}

\section{Introduction}

Prison studies are not unconnected with broader theoretical debates on 7 categories of identity and social life such as gender, ethnicity/race, class 8 and the intersections between these categories. Gender, however, has 9 informed prison research in a peculiar way. The very descriptive reference 10 to gender, to begin with, or the lack of it, is not itself gender-neutral and 11 appears to depend on the gender of those imprisoned. A random glance 12 through publications in prison studies will likely show that an explicit 13 mention of gender finds its way to the title only if a penal institution or 14 carceral research site imprisons women. This institution will appear des- 15 ignated as a 'women's prison'. Single-word 'prisons', without gender spec- 16 ifications, are male by default, unless they are the objects of a specific 17 comparison with their female counterpart.

(UID/Ant/04038/2013)

M. I. Cunha $(\bowtie)$

CRIA, 1 Universidade do Minh, Braga, Portugal 
This dual pattern of identification of prisons for men and prisons for women is far from being a simple effect of disproportion in numbers of men and women prisoners, or of relative carceral demography, in which women are invariably in the minority. Rather, it is a discrepancy that matches the asymmetry characterizing the history of prison research itself, which in turn is not altogether immune to long-standing gender issues of symbolic domination and inequality. Research on men's imprisonment has framed the debate in a universal mode, oblivious to gender. It is true that this research has more recently come to acknowledge the gender dimension, especially by focusing on the ideologies of masculinity that shape prison culture (Newton 1994; Sabo et al. 2001). Research on women's prisons, however, was built on the very basis of gender and has tended to be more gender-bound as a whole.

Besides having informed a reflexive agenda addressing issues of representation, such as the conundrums of representing women as victims and/or agents (Fili 2013), the angle of gender has presided over most research issues. Among the most pervasive is the gendered nature of prison regimes, whether they are portrayed as based on normative femininity and domesticity, or as more gender-neutral (Bosworth 1999; Carlen 1983; Kruttschnitt and Gartner 2005; Miller and Carbone-Lopez 2013; McCorkell 2003). Another prominent topic is the gendered character of prison cultures, socialities and 'pains of imprisonment', presented as predicated on gender roles and identities, and contrasted with their male equivalents (Giallombardo 1966; Heffernan 1972; Walker and Worrall 2000; Ward and Kassebaum 1965; Zaitzow and Thomas 2003). Overall, the characterization of the former has been endowed with a distinctly comparative tone, perhaps owing to the fact that configurations found within men's prisons were taken as the compass and reference model for analysing women's.

One example can be found in the depiction of prison cultures-a pervading topic in the study of prisoners' social world. Where women prisoners were concerned, either this sub-culture was deemed nonexistent or considered an inverted version of the male one. In the first case, descriptions were in the negative mode: the absence of cohesion and solidarity among women prisoners (that is, by reference to the forms it took in men's institutions), the absence of groups, the absence 
of an 'inmate code' and the absence of a local repertoire of social roles, 56 which in turn was also absent from a less complex prison slang (e.g. 57 Ward 1982; Tittle 1969; Kruttschnitt 1981; Williams and Fish 1974). 58 In the second case, characterizations were made by contrast. Women's 59 prison culture was supposedly based on pseudo-families and/or 60 homoaffective dyads (e.g., Selling 1931; Heffernan 1972; Foster 1975; 61 Giallombardo 1966; Ward and Kassebaum 1965; Statler 1986). Both 62 phenomena have been described mostly as an emotional response to 63 the deprivation of affection, ignoring other kinds of social and identity 64 dimensions. This emphasized the contrast between the nature of 65 women aggregates and the structure of male prisoners' sociality, which 66 $\begin{array}{ll}\text { was viewed mostly from a socio-economic angle. } & 67\end{array}$

As I have shown elsewhere (Cunha 1994), this long-standing ten- 68 dency to establish symmetrical contrasts between female and male 69 experiences of punitive confinement may have contributed to over- 70 simplifying and distorting far more complex realities. However, 71 favouring different descriptive models to account for men and wom- 72 en's carceral configurations-one more 'psychological', the other more 73 'sociological' - was not entirely new. To a certain extent, it recreated 74 within prison studies the trajectory of perspectives on male and female 75 criminality, respectively. While in mid-twentieth century the social, 76 economic and cultural dimensions of crime were increasingly high- 77 lighted, this did not occur evenly in theoretical perspectives on both 78 genders. Approaches to female criminality would still remain excluded 79 from this inflection for a long time (Smart 1977; Heidensohn 1985; 80 Dobash et al. 1986).

Nowadays, this more 'gendercentric' agenda is nevertheless increas- 82 ingly diversified for theoretical and empirical reasons alike. These involve 83 recognition of the diversity of women prisoners' experiences and identi- 84 ties and attention to a wider variety of aspects of carceral life, but also 85 changes inside and outside prison walls (e.g. Boutron and Constant 86 2013; Greer 2000; Mandaraka-Sheppard 1986; Owen 1998; Rowe 87 2011). Drawing on fieldwork in a Portuguese carceral setting in different 88 decades, I propose to contribute an additional aspect to this debate by 89 focusing on contextual shifts in the actual (current?) saliency of gender as 90 
a category of identity and social life in women's prisons. These shifts have occurred without major changes in prison regimes, even if these have become formally less gendered. ${ }^{1}$

\section{A Changing Prison Landscape}

Portugal is no exception to the worldwide imbalance between men's and women's incarceration rates. Women have consistently been the minority among the population behind bars. Currently (and also until the 1990s) they represent less than $6 \%$ of the prison population. However, after the democratic revolution in 1974, which decriminalized one of the main causes of women's imprisonment during the dictatorship (prostitution), this proportion rose steeply during the second half of the 1990s up to nearly $10 \%$ by the end of the century—one of the highest percentages in the European Union.

In fact, during the 1990s the percentage of Portugal's population behind bars (men and women) registered an unprecedented increase, and Portugal attained one the highest imprisonment rates per 100,000 inhabitants (145) in the European Union. ${ }^{2}$ One of the aspects of this substantial change in the prison population was its massive provenance from the same low-income-stigmatized urban areas. As a result, co-prisoners were often neighbours, relatives or previous acquaintances, an aspect that altered the social world of prisons (cf. Cunha 2008, 2014). This was both a consequence of selective drug control (intensive law enforcement targeting specific areas) and of the workings of the Portuguese retail drug economy (Cunha 2005).

Although this change took place in both male and female prisons, it has been more concentrated-and therefore more conspicuous-in the latter. Its prominence in women's institutions stems partly from the relative homogeneity of their population. In the 1990s, the variety of offenses leading to women's imprisonment was sharply reduced. Although the population of male prisoners was also fairly homogeneous (property offenses and drug-related crimes accounted together for the majority of convictions), its internal distribution was more balanced than that of its female counterpart, which was concentrated overwhelmingly on drug 
trafficking. ${ }^{3}$ Drug-related offenses already stood out as an important cause of women's imprisonment in the 1980s, along with property offenses (Cunha 1994). But it has mainly been since the 1990s that they became a top cause of women's incarceration (Cunha 2002; Cunha and Granja 2014; Matos 2008; Matos et al. 2017).

Imprisoned women were involved mostly in small-scale drug trafficking, whether as international drug couriers, or in domestic retail 129 drug dealing (see below). Two scenarios have been reported in the rele130 vant literature in Portugal: (i) young women whose participation in drug 131 trafficking is associated with drug use and/or abusive male partners 132 (Matos 2008); (ii) primarily adult but also young women from economi133 cally depressed milieus for whom drug trafficking is an income-generat134 ing strategy often engaged in to support their households. These women 135 operate autonomously as free-lancers or in non-hierarchical partnerships 136 with neighbours or family members. This is mostly the case in domestic 137 drug trafficking, which reveals some particular aspects in Portugal (cf. Cunha 2005).

Be that as it may, women are proportionally more convicted to prison 140 sentences for drug-related offenses than men. The centrality of drug 141 offenses in women's convictions is also what has best explained the faster 142 rise of female incarceration rates: these are the crimes with the highest 143 conviction rates and are among the most harshly sentenced. This means 144 that the rise in women's incarceration rates owed little to possible changes in the way courts deal with this gender.

I conducted field research in the main Portuguese women's prison (Estabelecimento Prisional de Tires, Tires hereafter) in two periods that, in 145 146 147 148 retrospect, emerge as defining moments in a changing carceral sociology 149 (the late eighties and the late nineties, cf. Cunha 1994, 2002, 2008). ${ }^{4}$ 150 These two decades revealed in their most pronounced form different pat151 terns that can now be found combined or reproduced in other prison 152 settings, albeit more mitigated in some respects. This is the case, for 153 example, with the prison of Santa Cruz do Bispo (Estabelecimento 154 Prisional de Santa Cruz do Bispo), which was the object of a recent con155 trolled comparison with Tires (Cunha and Granja 2014). ${ }^{5}$ I will, there156 fore, focus on these different configurations as they emerged in a clearly 157 defined fashion in these two periods in Tires. ${ }^{6}$ 


\section{Gendered Regimes}

The 'therapeutic' approach that shaped the history of women's penitentiary regimes during the first half of the twentieth century (Carlen and Tombs 2006; Heidensohn 1985) ${ }^{7}$ never fully occurred in Portugal. Instead of a strong medical and psychiatric influence in the definition and implementation of these regimes, in Portugal the main concern at that time was to carry out a systematic programme for the 'moral regeneration' of delinquents (Cunha 1994). Against the backdrop of religious exhortation, discipline and ascetic austerity, the adopted treatment model was based on two ingredients, both drawing heavily on dominant gender ideologies: domesticity and motherhood. In Portugal as elsewhere, delinquent women were considered 'double deviants', that is, both as members of society and as members of their gender. Rehabilitation therefore meant putting them back on track for the female roles and spheres from which they had supposedly strayed.

This perspective was in perfect harmony with the state ideology of the Estado Novo dictatorial regime in Portugal (1933-1974) (Cunha 1994). Its symbolic conflation of 'home' and 'nation' presented women as the nation's ultimate moral base and emphasized the need for their dedicated performance as wives and mothers as the only route for women's social existence and participation in the collective destiny (see Beleza dos Santos 1947; Salazar 1977). This state ideology was at odds with social realities, in that it could only be fulfilled-or afforded-by the elites. With the exception of these groups, women in Portugal — and more so among the poor-have always resorted to work and wage labour as a survival strategy, without this being considered a transgression of a gender cultural script within their social milieus (Cole 1991; Pujadas 1994).

The above ingredients would nevertheless linger, albeit more tenuously, in prison institutions long after the democratic revolution of 1974 and still permeate prison life today. The first ingredient in this foundational treatment model was the inculcation of domestic habits (Cunha 1994, 2013). Tires was a clear illustration of this model. The penitentiary treatment program was built around domestic skills. This was expressed both in the spatial configuration of the institutional wards itself, as in the range of activities offered to prisoners. If laundry, cleaning and kitchen 
services were oversized, it was only because they were meant to respond not just to Tires prison's internal needs, but also to supply male prison facilities nearby. The whole rationale and organization of the domestic sphere was thus transferred to the carceral institution on a large scale. Most activities, whether for maintenance or production, were an extension of the domestic order.

The predominance of so-called feminine activities would last for 200 decades. Gradually, however, it would cease to be presented as a method or a program for regeneration, designed and pursued with that explicit purpose. It became a mere effect of the status quo and disengagement 201 202 from the outside world, which is not uncommon in these institutions (Goffman 1999 [1961]). It also reflected the occupational skills of inmates themselves, which were scant and for the most part limited to domestic training. Even in today's most 'modern' prison, Santa Cruz, the range of activities available is, with a few exceptions, mostly centred on the domestic sphere (Cunha and Granja 2014). In any case, the geography of gender would continue to sharply determine the prison regime.

A second ingredient in the moral regeneration which was shaped by 211 social notions of gender consisted of the attempt to instill feelings of maternal responsibility in inmates and cultivate mothering skills. Although permission to keep infant children in prison took the children's interests into account, it was primarily justified by the program's aim to educate the mothers. Aiming at the 'social promotion of the delinquent woman', it was determined that 'offspring, in the case of infants, should remain with the mothers so as to maintain and promote their sense of 212 213 214 215 216 217 218 natural responsibilities' (Pinto 1969, p. 56). Prison regulations also 219 explicitly stipulated that prisoners should be taught to attend to their infant children inside the institution and that children should spend time 220 221 with their mothers on a daily basis (Correia 1981, p. 279).

222

Official regulations and institutional rules have remained stable over time in their general principles: namely, the age limit for children allowed to live in the institution with their mothers (up to three years old, excep223 tionally five $)^{8}$; the provision of a day nursery within the prison com226 pound, but physically separated from prison blocks, where children 227 remain during mothers' working hours, and where they are cared for by 228 trained personnel; a prison wing that houses prisoners with children 
together. These conditions are common to most major women's prisons in the country. Although stable in these aspects, explicitly gendered moral considerations have since long been expunged from official decrees, and their focus has shifted from the moral regeneration of prisoners (via leading them into proper motherhood) to accommodating the interest of the child.

Considerations involving the mother role did not disappear from prison daily life however. They remained infused in informal institutional practices and interactions (cf. Cunha 1994; Cunha and Granja 2014). Prisoners continued to be aware that their inmate and mother conditions were somehow merged, and some went as far as to suspect that their performance as mothers was assessed in the same way as their behaviour as prisoners - that is, with the potential to influence parole board deliberations. In any case, they sense all too well that the in-prison relationship with their offspring, and the language of care itself, are inescapably encompassed in the coercive management of the 'total institution' (Cunha 1994; Goffman 1999 [1961]).

\section{Doing and Undoing Gender}

In the previous section it was suggested that women's penitentiary treatment in Portugal was dictated mainly by gender ideologies, insofar as it was aimed at returning delinquents to the 'feminine' roles they had supposedly deviated from. Thus, the institution insisted on motherhood as part of the penitentiary's program of moral regeneration. Yet, contrary to this gendered image of the stranded woman, inmates have for the most part tended to express conformity — not 'deviance' - to conventional definitions of their gender. In Tires during the 1980s, this conformity was even clearly inscribed in prisoners' sociality itself, which was centred on in-prison mother-child relationships or marital-like couples, and was otherwise highly atomized: inmates generally did not act nor see themselves as a group, and actually developed a refined rhetoric of mutual denigration. ${ }^{\text {? }}$ 
Although the importance of these dyadic relationships was expressed by inmates in the language of affection and emotions, the support they provided had an identitarian aspect that confirmed them first of all as relational beings, more specifically in the relational roles which were normative markers of their gender ('mother', 'wife'/'romantic partner'). Gender identity occupied the front stage of the prison scene, both by the way it was performed through this sociality and how it was repeatedly asserted in 'prison talk', which focused mainly on children and partners, namely, on how the separation from them was paramount among the 'pains of imprisonment'. In the case of women with children in prison, mothers' narratives express a highly idealized maternal self-image and focus on a recurrent theme: the way their children's presence fulfills them, helps them cope and softens their prison experience (Cunha 1994, p. 156; Cunha and Granja 2014; Serra and Pires 2004, p. 420).

Indeed, the gendered regime of the prison was amplified both by 262 263 264 265 266 267 268 269 270 271 272 273 274 275 women's discursive construction of gender and by prisoners' management of their stigmatized social identities (Cunha 1994). Motherhood 276 277 was an important aspect in this respect. As also noted by Palomar (2007, 278 p. 372), the prison environment does allow for experiencing motherhood 279 in new ways, creating new subjectivities through which mothers in turn re-signify previous experiences of maternity: sheltered from the pressures of everyday survival, poverty and violence, with time available to dedicate to their children (who now also receive specialized medical and psychological attention); constantly near their children and exposed to expert educational and pedagogical input and programs, they may experience a bond with their children with unprecedented intensity and endow it with a meaning that takes centre stage in their lives thereon. It is hardly surprising that in such a context motherhood becomes hyperbolized in narratives of personal identity, including the way it is perceived in retrospect or projected in the future.

280 281 282 283 284 285 286 287 288 289 290

Women's prisons like Tires invite and promote an exaltation of moth291 erhood not only because they have persistently emphasized reproduction and domesticity or because the idea of 'inmate fathers' is still as alien to prison organizations as the one of "inmate mothers" (and their 'special 292 293 294 needs') is central to women's. ${ }^{10}$ They also do so because their environment 
297 focuses on motherhood and the mother-child bond in a way that is 298 highly idealized and disconnected from the actual experiences and harsh 299 realities of these women's lives. Prisons thereby participate in the essen300 tializing of motherhood, both as a naturalized aspect of gender and as an ideal hardly within the reach of the populations it incarcerates. It is behind bars that mothers find the time, the structure or the resources necessary to measure up to such an ideal.

Not surprisingly, however, it is also behind bars that this ideal contributes to deepening feelings of self-blame, inadequacy and dysfunctionality in performing the mother role. ${ }^{11}$ Although motherhood is repeatedly invoked as a motive and justification for their offence ( $I$ did it for my children; I had to feed my kids) — thus as a gendered 'technique of neutralization' (to extend a term coined by Sykes and Matza [1957])—prisoners blame themselves, and are blamed by prison personnel, not only for having offended, but also for failing to live up to motherly responsibilities (Cunha 1994, p. 71).

Besides being a source of meaning that reshapes, recreates or reinvents a personal identity, motherhood in prison has conveyed, however, another identity effect as an anchor of a 'non-deviant' social identity. As I have detailed elsewhere (1994), in the eighties, the adherence to conventional gender roles also emerged as a way to shelter social identity from the stigma attached to imprisonment, that is, as a viable route to negotiate and exorcize stigma. In other words, the narrative importance of the 'good mother' was also instrumental in rejecting a "deviant" identity and invoked as a synonym of a 'good citizen'.

Ten years later, mothering and motherhood were less emphasized in identity management and in the prison social scene. Firstly, categories of identity and social forms were made more complex by hyperincarceration and by the co-imprisonment of relatives. Since the nineties, in-prison family forms have become more varied. The sociography of relatedness, as well as the 'ethics of care' once identified with women qua mothers, have no longer been limited to mother-child dyads anymore, but have involved wider circles of relationships (Cunha 2002, 2013). Co-imprisoned family members and other prisoners participate collectively in the in-prison care of children, for example, sharing food, affection and assistance. 
Furthermore, since co-imprisoned mothers and daughters were often both adults, and the ethics of care involved more than two generations simultaneously (see Cunha 2002, 2013), care is now enmeshed in a wider and more (even if not altogether) gender-neutral ethics of respect, reciprocity and moral obligation between family members. ${ }^{12}$ Daughters, as well as sons, are supposed to respect and support their parents within and from beyond prison walls. It is disrespectful not to be loyal, deferential, or not to reciprocate the care they received from their parents when they were children.

In addition, prison stigma ceased to be a crucial issue. Prison merely compounds the structural and symbolic marginalization that now affects imprisoned populations collectively and much more profoundly than before. Stigma is no longer negotiable-either through gender conformity or otherwise (Cunha 2008).

Finally, the prominence of gender identity in the prison scene would give way to a new sense of collective identity, based on the prisoners' sharing of a common provenance from the same destitute urban areas, on kin, friendship and neighbourhood ties, and on a shared position at the lowest level of the class structure. Class-based collective solidarities gained strength in the prison scenario and became an important facet of prisoners' social identity. There was now an unprecedented rhetoric of 'community', constantly reasserted in prison talk, reiterating the perception that we're all in the same boat, and sustaining wider forms of solidarity and resistance. The notion of a shared destiny was now emphasized over other identities_-gender and race/ethnicity alike (Cunha 2010). In the face of these collective categories of agency and identity, within which prisoners came to react to their common marginalization, other levels of identity such as gender became more discreet in prison life.

333

334 335 336 337 338 339 340 341 342 343 344 345 346 347 348 349 350 351 352 353 354 355 356 357 358 359 360

\section{$5 \quad$ Final Remarks}

Although prisons for men and for women are both gendered institutions, perspectives on these two kinds of settings have been unevenly gendered, and research on women's prisons has tended to be more gender-bound in general. This gendercentrism has partly been justified by the historical 
centrality of gender systems prioritizing reproduction and domesticity over other aspects of life in the definition of prison regimes for women. These aspects can be amplified by women prisoners' own discursive construction of gender and strategically emphasized in the management of stigmatized identities in the prison social scene. However, the very saliency of gender as a category of identity and social life can be highly contextual, even in confinement situations where there is more continuity than change in gendered prison regimes over time. Firstly, as we have seen, prisons reflect broader structural shifts that have a variable impact on forms of marginality and are not without influence on shaping different forms of stigmatization. Secondly, social identities are situational. For all the intersections-rightly indicated by intersectionalist perspectives - of gender, ethnicity/race, class and other facets of an altogether plural identity, these facets can nevertheless be more or less relevant in different social situations. Even taking into account the power structures that shape multiple aspects of identity, in some circumstances one facet can appear overshadowed or subdued in favour of other contextual variants of that identity.

The two ethnographic inquiries conducted in a women's Portuguese prison in different decades showed that while in the eighties gender identity occupied the front stage of the prison scene, ten years later the prominence of gender would give way to a new sense of collective identity and forms of relatedness, associated with hyper-incarceration and the co-imprisonment of relatives, friends and neighbours. In the face of this powerful collective identity with which prisoners came to react to their common deeper social marginalization, other levels of identity such as gender were played down and became less visible in the prison social scene. Gender still matters, evidently, and gender inequality has not become less relevant in shaping these women's lives. Nevertheless, these two inquiries led me to be cautious about treating gender as a fixed dimension of the prisoners' moral and social world, and showed the importance of historicizing gender in prison studies in more than one way.

In my own research, the focus on gender has followed the movement of my imprisoned interlocutors, and receded from the foreground to the background of the analysis. As an analytical angle it remained important 
to situate women's participation in the drug economy, the repression of 402 which triggered a rise in imprisonment rates, and to investigate the 403 reasons these rates rose faster for women than for men. Otherwise, I con- 404 sidered a women's prison like Tires mainly as a vantage point to better 405 capture important processes linking prisons to a range of economically 406 depressed urban neighbourhoods, as well as the resulting sociological 407 mutations that emerged in prison life by the end of the century. These 408 mutations affected both male and female prison settings, but were more 409 clearly visible in women's (cf. Cunha 2002, 2008). 410

Taken together, the two inquiries informing this chapter can contrib- 411 ute to a reflection on how a more or less important focus on gender 412 should be decided less on the basis of general agendas (theoretical or 413 political), than on the basis of gender's contextual importance, specifi- 414 cally assessed. In other words, the emphasis on gender should itself be 415 treated as an empirical question, that is, according to the relative rele- 416 vance of gender as a category of identity, and depending on its variable 417 $\begin{array}{ll}\text { potential to organize social relations. } & 418\end{array}$

\section{Notes}

1. The tensions between what is formally defined in the legal requirements (which promote gender equality) and everyday social practices are par420 ticularly visible in parenting in prison, for example. Prison regulations have also incorporated the principles of neutrality and formal equality between women and men. Currently, the law regulating children's stay in prison is gender neutral; that is, both imprisoned mothers and fathers are allowed to keep their offspring with them inside prison facilities (Law $115 / 2009)$. However, the implementation of this principle is unequal. Logistics and practical dispositions render most men's prisons hardly suitable for children to reside with their imprisoned fathers. For example, there are no day-care centres in male institutions, nor adequate cells that are physically separated from other prison blocks (cf. Law 51/2011). Furthermore, although the need to meet female prisoners' 'special needs' regarding motherhood is mentioned in state guidelines about parenting in prison, there is no equivalent reference regarding fathering (Law $115 / 2009)$. 
2. Estatísticas da Justiça, Ministério da Justiça (1987-2000).

3. As an example analysed in Cunha's study (2002) documenting these shifts during the 1990s, in 1997 46\% of incarcerated men were imprisoned for property offenses and 34\% for drug-related crimes, against $16 \%$ and $69 \%$, respectively, in the female case (Estatisticas da Justiça, Ministério da Justiça, 1997).

4. Fieldwork was conducted in two- and one-year periods (1987-1989 and 1997, respectively). It benefitted from unrestricted access to all prison facilities. Besides 70 in-depth interviews, this allowed for the observation and participation in most prison activities and daily life, as well as for engaging in informal individual and group conversations with prisoners on a regular basis and under varied circumstances. In both periods a trusting relationship with prisoners was established, although not at the same pace or by the same processes (see Cunha 2002). In both periods women were selected by combining a snowball progression that followed 'natural' networks and a systematic sampling that diversified inmates along lines of penal and social profile, as well as length and experience of confinement (Cunha 1994, 2002).

5. Tires was created in 1954 on the outskirts of Lisbon and continues to be the main female penal institution in the country; Santa Cruz opened in 2005 near the northern city of Oporto, and was intended for a similar kind of penal population.

6. The prison population of Tires, which in 1997 reached 823 inmates, had developed a striking social and penal homogeneity in the span of only a decade. In 1997, a total of $76 \%$ of the women there were imprisoned for drug trafficking, compared to the $37 \%$ registered 10 years earlier, and property offenders represented no more than $13 \%$. The majority of those convicted (69\%) were serving sentences of more than five years. Prisoners increasingly came from the segments of the working class most deprived of economic and educational capital: from 1987 to 1997 the proportion of women who held jobs in the bottom tier of the service economy rose from $4 \%$ to $33 \%$, and the proportion of those who had never attended school or gone beyond the fourth grade rose from $47 \%$ to $59 \%$. A significant proportion of prisoners had relatives imprisoned in the same institution or in other prison facilities. According to a conservative estimate based on data registered in social-educational files, between onehalf and two-thirds of the inmates in Tires had family members inside the same institution (sisters, cousins, aunts, nieces, mothers, grandmothers). This estimate does not include male partners and kin serving their own sentences in other facilities. 
7. Based on neo-Lombrosian perspectives addressing female criminality, during the first half of the 20th century prison policies in some European 476 countries and in the United States adopted a therapeutic treatment based 477 on medical and psychiatric intervention. Although this trend has lessened over the years, according to Carlen and Tombs (2006) there is a revival of these approaches in policies that address women's socio-economic problems by repositioning them as 'cognitive' problems.

8. For recent general regulations see the General Regulation for Portuguese Prisons, Law 51/2011.

9. Among other examples of mutual disqualification, one prisoner could justify her offence as a fortuitous result of unique circumstances, while essentializing those of her companions as matters of a criminal nature (cf. Cunha 1994, 2008, for development of this point).

10. For the way prisons and the judicial system fail to include fathers in shar489 ing the burdens of parenthood see Palomar (2007) and Machado and 490 Granja (2013).

491

11. This ideal further excludes fathers and exonerates them from their own emotional, socio-economic and moral responsibilities.

492

493

12. Mothers, grandmothers, mothers-in-law, aunts, cousins, sisters and 494 sisters-in-law now find themselves doing time together, in a circle of kin 495 that often amounts to more than a dozen people, sometimes encompassing four generations (when a great-grandson is born in prison to a prisoner whose daughter and granddaughter are also imprisoned).

496 497 498

\section{References}

Beleza dos Santos, J. (1947). Nova organização prisional Portuguesa. Coimbra: 500 Coimbra Editora.

Bosworth, M. (1999). Engendering resistance: Agency and power in women's pris502 ons. Dartmouth: Ashgate.

Boutron, C., \& Constant, C. (2013). Gendering transnational criminality. The 504 case of women's imprisonment in Peru. Signs, 39(1), 177-195. 505

Carlen, P. (1983). Women's imprisonment: A study in social control. London: 506 Routledge \& Kegan Paul.

Carlen, P., \& Tombs, J. (2006). Reconfigurations of penality. The ongoing case 508 of the women's imprisonment and reintegration industries. Theoretical 509 Criminology, 10(13), 337-360. 
Cole, S. (1991). Women of the praia. Work and lives in a Portuguese coastal community. Princeton: Princeton University Press.

Correia, A. M. (1981). Tratamento penitenciário. Lisbon: Centro do Livro Brasileiro.

Cunha, M. I. (1994). Malhas que a reclusão tece. Questóes de identidade numa prisão feminina. Lisbon: CEJ.

Cunha, M. I. (2002). Entre o Bairro e a Prisão: Tráfico e Trajectos. Lisbon: Fim de Século.

Cunha, M. I. (2005). From neighborhood to prison: Women and the war on drugs in Portugal. In J. Sudbury (Ed.), Global lockdown: Imprisoning women (pp. 155-165). New York/London: Routledge.

Cunha, M. I. (2008). Closed circuits: Kinship, neighborhood and imprisonment in urban Portugal. Ethnography, 9(3), 325-350.

Cunha, M. I. (2010). Race, crime and criminal justice in Portugal. In A. KaluntaCrumpton (Ed.), Race, crime and criminal justice: International perspectives (pp. 144-161). New York: Palgrave Macmillan.

Cunha, M. I. (2013). The changing scale of imprisonment and the transformation of care: The erosion of the 'welfare society' by the 'penal state' in contemporary Portugal. In M. Schlecker \& F. Fleischer (Eds.), Ethnographies of social support (pp. 81-101). New York: Palgrave Macmillan.

Cunha, M. I. (2014). The ethnography of prisons and penal confinement. Annual Review of Anthropology, 43(1), 217-233.

Cunha, M., \& Granja, R. (2014). Gender asymmetries, parenthood and confinement in two Portuguese prisons. Champ Pénal/Penal Field, XI. https:// doi.org/10.4000/champpenal.8809.

Dobash, R., Dobash, E., \& Gutteridge, S. (1986). The imprisonment of women. Oxford: Basil Blackwell.

Fili, A. (2013). Women in prison: Victims or resisters. Representations of agency in women's prisons in Greece. Signs, 39(1), 1-26.

Foster, T. (1975). Make-believe families: A response of women and girls to the deprivations of imprisonment. International Journal of Criminology and Penology, 3, 71-78.

Giallombardo, R. (1966). Society of women. A study of a Women's prison. New York: Wiley.

Goffman, E. (1999 [1961]). Asylums. Essays on the social situation of mental and other inmates. New York: Garden Books.

Greer, K. (2000). The changing nature of interpersonal relationships in a women's prison. Prison Journal, 80(4), 442-468. 
Heffernan, E. (1972). Making it in prison. The square, the cool and the life. 549 New York: Wiley.

Heidensohn, F. (1985). Women and crime. London: Macmillan. 551

Kruttschnitt, C. (1981). Prison codes, inmate solidarity and women: A reexami- 552 nation. In M. Warren (Ed.), Comparing Male and Female Offenders (pp. 143- 553 141). London: Sage. $\quad 554$

Kruttschnitt, C., \& Gartner, R. (2005). Marking time in the golden state: Women's 555 imprisonment in California. Cambridge: Cambridge University Press. 556

Law 115. (2009, October 12). Código da Execução das Penas e Medidas 557 Privativas da Liberdade, Diário da República, 1(197). 558

Law 51. (2011, April 11). Regulamento Geral dos Estabelecimentos Prisionais, 559 Diário da República, 1(71). 560

Machado, H., \& Granja, R. (2013). Paternidades fragmentadas. Género, 561 emoções e (des)conexões biogenéticas e prisionais. Análise Social, 208, 562 xlviii(3), 550-571. 563

Mandaraka-Sheppard, A. (1986). The dynamics of agression in women's prisons in 564 England. London: Gower. 565

Matos, R. (2008). Vidas raras de mulheres comuns: Percursos de vida, significaçôes 566 do crime e construção da identidade em jovens reclusas. Coimbra: Almedina. $\quad 567$

Matos, R., Cunha, M., Carvalho, P., Tavares, R., \& Miranda Pereira, L. (2017). 568 Women in prison. Portugal. In P. Hein van Kempen \& M. Krabbe (Eds.), 569 Women in prison. The Bangkok rules and beyond, International Penal and 570 Penitentiary Foundation (Vol. 46, pp. 613-644). Portland: Intersentia 571 Uitgevers N.V. $\quad 572$

McCorkell, J. A. (2003). Embodied surveillance and the gendering of punish- 573 ment. Journal of Contemporary Ethnography, 32(1), 41-76. 574

Miller, J., \& Carbone-Lopez, K. (2013). Gendered carceral regimes in Sri- 575 Lanka: Colonial laws, post-colonial practices and the social control of sex 576 workers. Signs, 39(1), 79-103. 577

Newton, C. (1994). Gender theory and prison sociology: Using theories of mas- 578 culinities to interpret the sociology of prisons for men. The Howard Journal of 579 Criminal Justice, 33, 193-202.

580

Owen, B. (1998). In the mix: Struggle and survival in a women's prison. Albany: 581 State University of New York Press. 582

Palomar Verea, C. (2007). Maternidad en prisión. Guadalajara: Universidad de 583 Guadalajara.

584

Pinto, J. R. (1969). O tratamento penitenciário de mulheres. Boletim da admin- 585 istração penitenciária e dos institutos de criminologia, 25: 21-91. 
587

588

589

590

591

592

593

594

595

596

597

598

599

600

601

602

603

604

605

606

607

608

609

610

611

612

613

614

615

616

617

Pujadas, J. (1994). Processos sociais e construção de identidades nas periferias urbanas: os casos de Lisboa e Catalunha. Mediterrâneo, 4, 11-19.

Rowe, A. (2011). Narratives of self and identity in women's prisons: Stigma and the struggle for self-definition in penal regimes. Punishment and Society, 13, 571-591.

Sabo, D., Kupers, T. A., \& London, W. (Eds.). (2001). Prison masculinities. Philadelphia: Temple University Press.

Salazar, A. O. (1977). Como se levanta um Estado. Lisbon: Golden Books.

Selling, L. (1931). The pseudo-family. American Journal of Sociology, 37, 247-253.

Serra, D., \& Pires, A. (2004). Maternidade atrás das grades: Comportamento parental em contexto prisional. Análise Psicológica, 2(XXII), 413-425.

Smart, C. (1977). Women, crime and criminology. London: Routledge \& Kegan Paul.

Statler, J. (1986). Mitchellville: A study of the adaptation responses of women in prison. $\mathrm{PhD}$ dissertation, Iowa State University.

Sykes, G., \& Matza, D. (1957). Techniques of neutralization: A theory of delinquency. American Sociological Review, 22(6), 664-670.

Tittle, C. (1969). Inmate organization: Sex differentiation and the influence of criminal sub-cultures. American Sociological Review, 34, 492-505.

Walker, S., \& Worrall, A. (2000). Life as a woman. The gendered pains of indeterminate imprisonment. Prison Service Journal, 132, 27-37.

Ward, J. (1982). Telling tales in prison. In R. Frankenberger (Ed.), Custom and conflict in British society (pp. 234-257). Manchester: Manchester University Press.

Ward, D., \& Kassebaum, G. (1965). Women's prison: Sex and social structure. Chicago: Aldine.

Williams, V., \& Fish, M. (1974). Convicts, codes and contraband: The prison life of men and women. Cambridge: Ballinger.

Zaitzow, B., \& Thomas, T. (Eds.). (2003). Women in prison: Gender and social control. Boulder: Lynn Rienner Publishers. 